\title{
内頸動脈永久閉塞後の遅発性脳虚血
}

\author{
池田 圭朗, 松山 眞千, 矢崎 貴仁 \\ 河瀬 斌, 塩原 隆造, 戸谷 重雄
}

\section{Delayed Ischemia After Permanent ICA Occlusion}

Keiro Ikeda, M.D., Masayuki Matsuyama, M.D., Takahito Yazaki, M.D., Takeshi Kawase, M.D., Ryuzo Shiobara, M.D., and Shigeo Toya, M.D.

Department of Neurosurgery, Keio University School of Medicine, Tokyo, Japan

\begin{abstract}
Summary : The internal carotid artery was occluded by means of intravascular balloon or surgical ligation in 12 cases with negative study of preceeded balloon Matas tests. Of 12 cases, 7 were cerebral aneurysms, 4 carotid-cavernous fistulas (CCF), and one cavernous sinus meningioma. Delayed ischemic symptoms appeared in three of those during the follow-up period after the occlusion. One of them developed hemiplegia 4 days after the proximal ligation, another patient suffered numbness of the left upper extremity a few weeks after occlusion of the ICA, and the third cases sustained a transient ischemic attack 5 years after the operation. Mean stump pressure (MSP) and/or tomographic cerebral blood flow (CBF) measured after ICA occlusion were slightly decreased, but still above the critical value. A focal ischemic region was found in the territory of perforating arteries in 2 of 3 cases. In those patients, postocclusion blood pressure and/or flow studies turned out to be of less value in predicting delayed ischemic symptoms, because the perforating arteries rather than the cortical branches seemed to take part in the symptomatic ischemia. Antiplatelet agents might be nesessary to prevent the delayed ischemic complication after permanent ICA occlusion.
\end{abstract}

$$
\text { はじめに }
$$

直達手術不能な内頸動脈領域の動脈瘤に対して，あるい は内頸動脈を犠牲にせざるをえない頭蓋底腫瘍に対して以 前より内頸動脈の ligation あるいは balloon occlusion が行 われてきた 1) -5)7９１１0)。このような内頸動脈を永久閉塞せ ざるをえない症例において血行再建を行う必要があるかど うかに関しては議論の多いところであり, その適応を考え る上で永久閉塞後の虚血症状を予測できるかどうかは重要 な問題である。近年, balloon Matas testにおいて, 神経 症状発現の有無のほか, EEG 変化 ${ }^{8)}{ }^{10)}$, stump pressure ${ }^{2)}$ ${ }^{6)}$, dynamic $\mathrm{CT}^{5 \text { 11) }}$ やゼノン $\mathrm{CT}(\mathrm{Xe}-\mathrm{CT})^{2) 7) 9)}$ 上の脳血
Key words :

- carotid aneurysm

- carotid occlusion

- carotid blood flow

- carotid ischemia

- arterial reconstruction

慶應義塾大学 脳神経外科(受稿日 1992.6.8)〔連絡先：干160 東京都新宿区信濃町 35 慶應義塾大学医学部 脳神経外科 池田圭朗〕 
頸動脈瘤 7 例, 外傷性内頸動脈海綿静脈洞瘻 (CCF) 4 例, および海綿静脈洞内髄膜腫 1 例)を対象とした(Table 1). 男性 4 人, 女性 8 人, 年歯令は 16 歳から 66 歳, 平均 37 歳 であった. 内頸動脈閉塞は 9 例が血管内 balloonによって 3 例が観血的にいずれも頭蓋外で行われ，術後 $2 \sim 3$ 週間 は血小板抑制剂を使用した。 balloon Matas test および mean stump pressure (MSP)の測定は次のように行った. 大腿動脈より内頸動脈に誘導された double-lumen catheter の balloon 側 catheterに造影剂を注入して, ゆっくり balloon を膨らませ, back pressure の低下が見られたとこ ろで他側 catheterに造影剤を注入する，balloonの末梢に 造影剤が停滞すれば，内頸動脈は完全に閉塞していること になる.この時点から 10〜15 分間，神経症状の発現の有 無を観察するとともにMSP を測定したままた，MSP と 平均全身血圧 (MABP) との比 (\% MSP) を計算した。 XeCT を施行した 6 例は 1 例を除き，内頸動脈閉塞後 2 週間 以内に再循環式吸入器を使用した呼気法で行い, OM line より $5 \mathrm{~cm}$ 上方の断面に含まれる脳血流量の平均を算出し て大脳半球平均血流量とした。 また，やはり内頸動脈閉塞 後 2 週間以内に 2 例で perfusamin (HM-PAO)を用いた SPECT を施行した. 追跡期間は 6 力月から 8 年 4 力月, 平均 4 年 10 カ月であった。

\section{結果}

balloon Matas test が陰性であったにもかかわらず，内 頸動脈永久閉塞後に虚血症状を生じた, いわゆる遅発性脳
Table 1 Clinical materials

12 cases of permanent occlusion of the ICA with the negative balloon Mates test

\begin{tabular}{ll}
\hline IC aneurysm & 7 \\
Traumatic CCF & 4 \\
Cavernous meningioma & 1 \\
\hline
\end{tabular}

虚血は 12 例中 3 例にみられた (Table 2). その 3 例を提示 する。

$<$ 症例 $2>66$ 歳, 女性.

術前症状は右眼の進行性視力障害で, 脳血管写上, 右内 頸動脈 $\mathrm{C}_{1}-\mathrm{C}_{3}$ portion の巨大脳動脈瘤を認めた. balloon

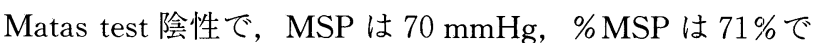
あった. $\mathrm{C}_{4}$ portion でバルーンを膨らませ，内頸動脈を閉 塞させた (Fig. 1). 術後, 特に問題なく経過していたが 4 日目より左の片麻痺が出現し，次第に進行，完全麻痺とな ったＣT 上，動脈瘤および内頸動脈の血栓化と右前脈絡 叢動脈領域の梗塞を認めた(Fig. 2, 3)。これは右前脈絡叢 動脈が動脈瘤から派生していたため動脈瘤血栓化とともに 閉塞し，穿通枝領域に限局した梗塞を生じたと考えられた。 また，閉塞後 49 日目に施行したXe-CT で大脳半球平均血 流量は両側とも $33 \mathrm{ml} / 100 \mathrm{~g} / \mathrm{min}$ と中等度の低下を示し, 右大脳半球には watershed zone の血流低下を認めたがこ の部分には CT 上梗塞は出現せず, 左片麻痺の原因とは考 えられなかった(Fig. 3)。

Table 2 Clinical summary

\begin{tabular}{|c|c|c|c|c|c|c|c|}
\hline \multirow{2}{*}{$\begin{array}{l}\text { Patient } \\
\text { No. }\end{array}$} & \multirow{2}{*}{$\begin{array}{l}\text { Age } \\
\text { Sex }\end{array}$} & \multirow{2}{*}{ Diagnosis } & \multirow{2}{*}{$\begin{array}{c}\text { MSP } \\
(\mathrm{mmHg})\end{array}$} & \multirow{2}{*}{$\% \mathrm{MSP}$} & \multicolumn{2}{|c|}{$\begin{array}{l}\text { Hemispheric CBF } \\
(\mathrm{m} l / 100 / \mathrm{min})\end{array}$} & \multirow{2}{*}{$\begin{array}{l}\text { Delayed ischemic } \\
\text { symptoms after } \\
\text { occlusion }\end{array}$} \\
\hline & & & & & $\begin{array}{l}\text { occluded } \\
\text { side }\end{array}$ & $\begin{array}{l}\text { contralateral } \\
\text { side }\end{array}$ & \\
\hline 1 & $52 \mathrm{M}$ & ICA aneurysm & 65 & 54 & not done & & \\
\hline 2 & $66 \mathrm{~F}$ & ICA aneurysm & 70 & 71 & 32.7 & 33.4 & Lt. hemiplegia \\
\hline 3 & $16 \mathrm{~F}$ & ICA aneurysm & 74 & 65 & 73.9 & 80.9 & \\
\hline 4 & $35 \mathrm{~F}$ & ICA aneurysm & 100 & 100 & not done & & \\
\hline 5 & $25 \mathrm{M}$ & ICA aneurysm & 53 & 45 & 41.3 & 57.7 & \\
\hline 6 & $50 \mathrm{~F}$ & ICA aneurysm & 41 & 54 & not done & & \\
\hline 7 & $35 \mathrm{M}$ & ICA aneurysm & 83 & 67 & not done & & \\
\hline 8 & $16 \mathrm{M}$ & traumatic $\mathrm{CCF}$ & 50 & 50 & 40.1 & 48.0 & \\
\hline 9 & $20 \mathrm{M}$ & traumatic $\mathrm{CCF}$ & not done & - & 66.9 & 66.6 & \\
\hline 10 & $55 \mathrm{~F}$ & traumatic $\mathrm{CCF}$ & 75 & 68 & not done & & \\
\hline 11 & $20 \mathrm{M}$ & traumatic $\mathrm{CCF}$ & not done & - & 33.9 & 34.6 & $\begin{array}{l}\text { amaurosis } \\
\text { fugax }\end{array}$ \\
\hline 12 & $42 \mathrm{~F}$ & meningioma & 95 & 82 & $\begin{array}{l}\text { perforator } \\
\text { ischemia } \\
\text { (SPECT) }\end{array}$ & & $\begin{array}{l}\text { numbness in the } \\
\text { Lt. upper extremity }\end{array}$ \\
\hline
\end{tabular}




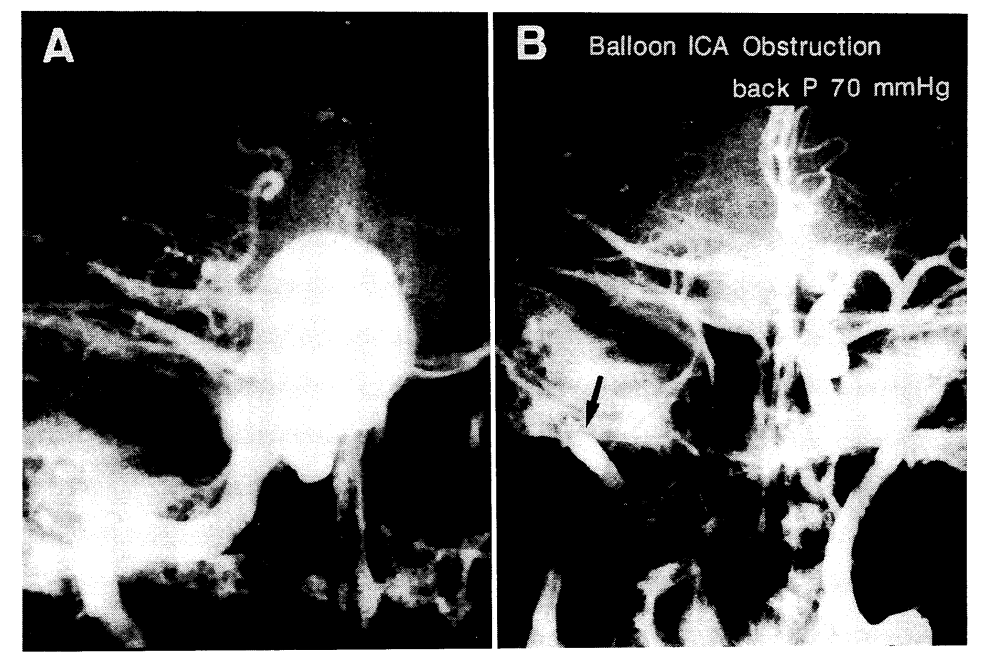

Fig. 1 Case 2. A: Right carotid arteriogram showing a giant IC aneurysm with a broad neck from $\mathrm{C}_{1}$ to $\mathrm{C}_{3}$. B: Left carotid arteriogram after balloon occlusion (arrow).

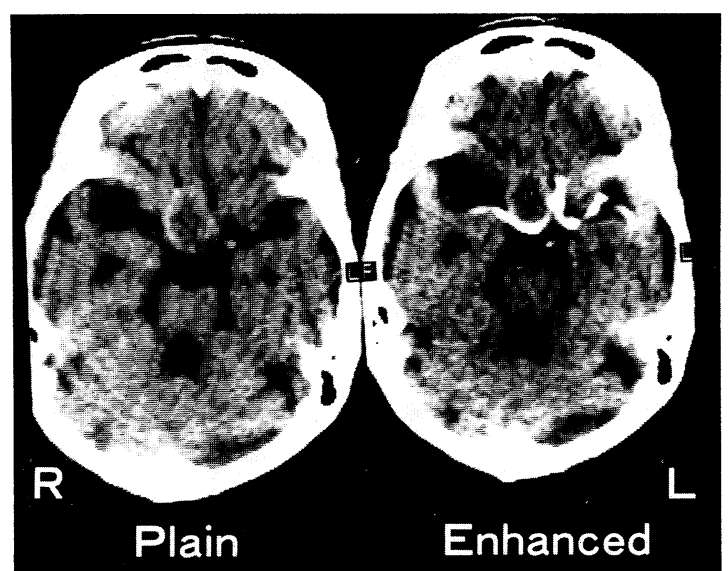

Fig. 2 Same case as in Fig. 1. CT scan showing the thrombosed aneurysm.

<症例 11>32 歳, 女性.

外傷性 CCF にて右眼球突出，複視を生じた. balloon Matas test で陰性を確認後，右内頸動脈を $\mathrm{C}_{4}$ portion で閉 塞させた。術後 2 日目に施行したXe-CT で半球血流量は 患側 33.9，健側 34.6 であった(Fig. 4). 神経脱落症状な く退院した後，外来通院していたが，5年後に amaurosis fugax と思われる一過性の右眼視力障害をきたした。この とき, 眼底に塞栓症を思わせる所見なく，血圧も低かった ため，症状は low perfusionによる可能性があると思われ た。しかし， cortical atrophyなどの長期低灌流所見は見 られなかった。

\section{$<$ 症例 12>42 歳. 女性.}

右視力低下を主訴として来院し, MRI で右海綿静脈洞 への腫瘍侵潤が明らかとなった（Fig. 5)。また，脳血管写 では $\mathrm{C}_{4}$ に軽度狭窄がみられた. balloon Matas test 陰性 で, MSP は $95 \mathrm{mmHg}$ \% MSP は $82 \%$ と十分であったた

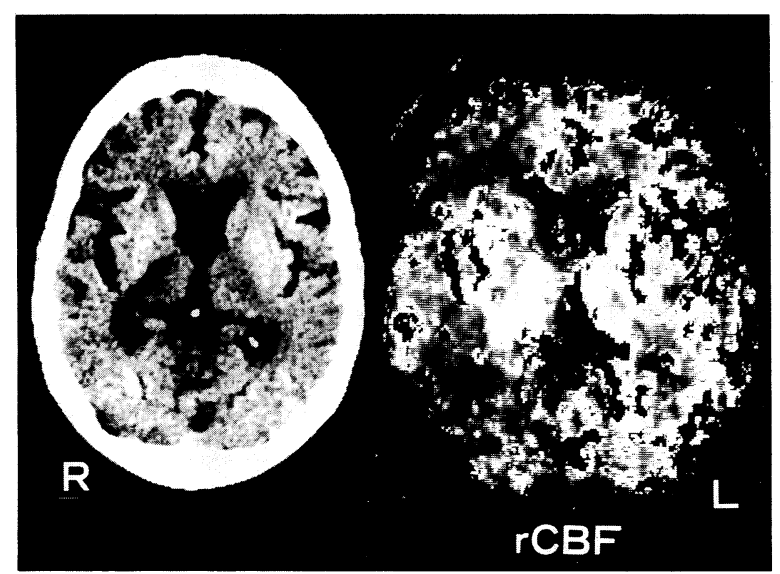

Fig. 3 Same case as in Fig. 1. CT and Xe-CT performed 6 weeks after occlusion of the ICA. Left: Plain CT scan showing a low density area in the distribution of the anterior choroidal artery. Right: Xe-CT showing low $\mathrm{CBF}$ in both cerebral hemispheres.

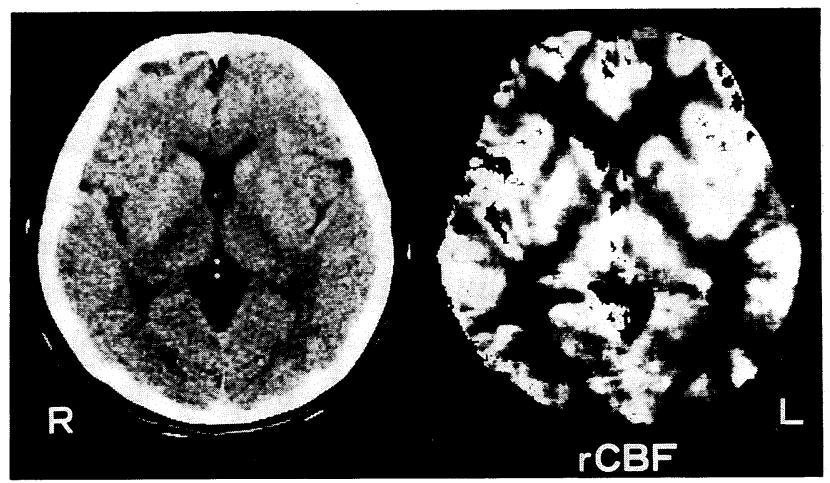

Fig. 4 Postocclusion CT and Xe-CT in Case 11. Left: Plain CT scan showing absence of low density area. Right: Xe-CT showing symmetrical decrease in $\mathrm{CBF}$. 


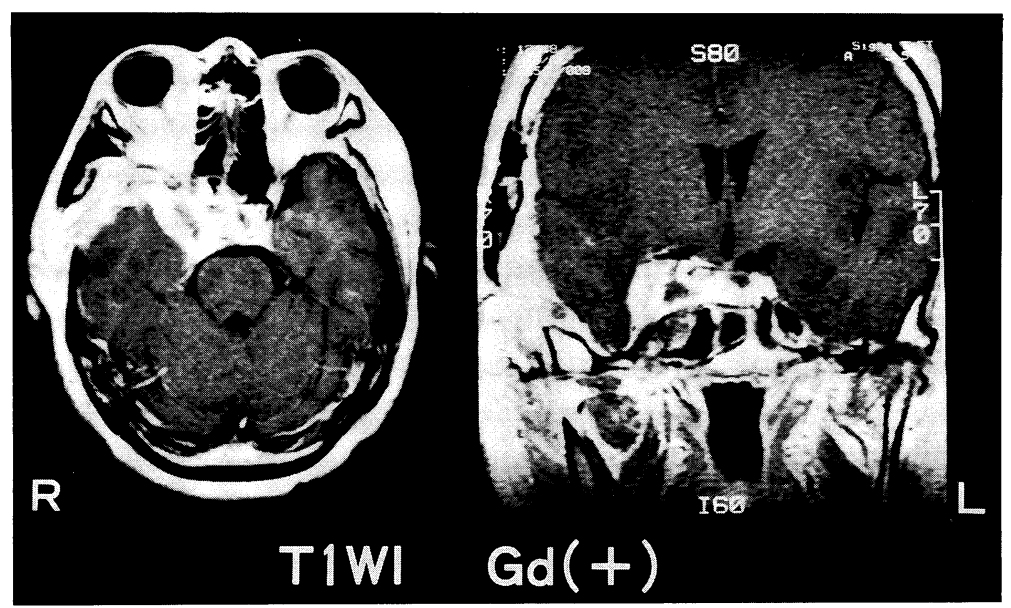

Fig. 5 Case 12. MRI demonstrating tumor growth into the right cavernous sinus. Left: axial view; right: coronal view. The carotid artery is encased.

め 2 期手術とし，まず，右内頸動脈を総頸動脈からの起始 部で結禁した。術後, 患者は左上肢に限局性のしびれを訴 えた. 脳血管写を施行したところ, 術前の右内頸動脈写で は描出されていた右後交通動脈が左内頸動脈写で描出され なかった。なお, 同動脈写で右中大脳動脈は開存していた。 このとき, CT 上低吸収域は認めなかったが SPECT で右 視床付近の血流低下を認めた。また, SPECT 上で皮質領 域の血流低下はなかった(Fig. 6). その後, 数週間でしび れは消失し, 予定どおり腫瘍摘出術が行われた. 現在, 半 年を経て，虚血症状は出現していない.

\section{[データの総括 $]$}

balloon Matas test でMSP を測定しえた患者 10 人の測 定值は $40 \sim 60 \mathrm{mmHg} 3$ 人, $60 \sim 80 \mathrm{mmHg} 4$ 人, 80 $\mathrm{mmHg}$ 以上 3 人であった。虚血症状を生じた 2 人はそれ ぞれ $70 \mathrm{mmHg}$ および $95 \mathrm{mmHg}$ と, むしろ比較的高值で あった (Table 2). \% MSP は 40〜60\% 4 人，60〜80\% 4 人, $80 \%$ 以上 2 人であり, 虚血症状を生じた 2 人はやはり $71 \%$ および $82 \%$ と高值であった (Table 2). 次に内頸動脈 閉塞後 Xe-CT を施行した 6 人の患側半球平均血流量は 30 $\sim 40 \mathrm{ml} / 100 \mathrm{~g} / \mathrm{min} 2$ 人, $40 \sim 50 \mathrm{ml} / 100 \mathrm{~g} / \mathrm{min} 2$ 人, 50 $\mathrm{m} l / 100 \mathrm{~g} / \mathrm{min}$ 以上 2 人であり, 虚血症状を生じた 2 人の 患側半球平均血流量は 32.7 および $33.9 \mathrm{ml} / 100 \mathrm{~g} / \mathrm{min}$ で あった(Table 2).

\section{考察}

内頸動脈瘤や頭蓋底腫瘍の治療では内頸動脈を永久閉塞 せざるをえない症例があり, balloon Matas test で陰性を 確認する必要がある。しかし, balloon Matas test が陰性 である,つまり 15 分程度の内頸動脈閉塞で虚血症状が出

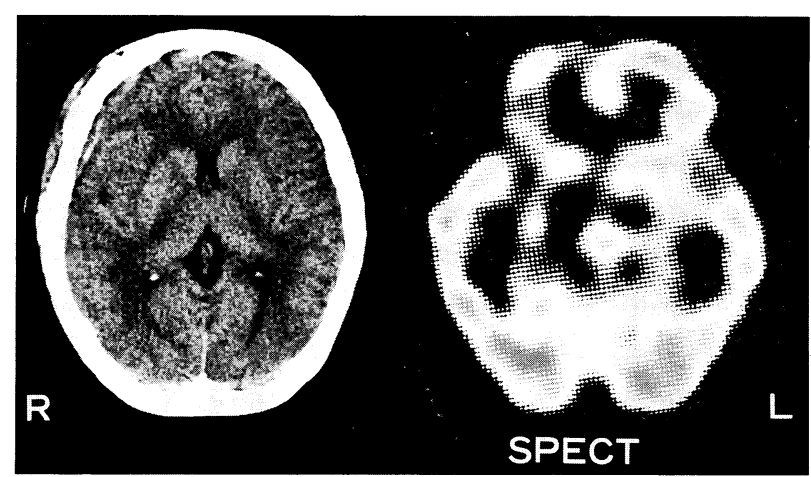

Fig. 6 Postocclusion CT and SPECT in the same case as in Fig. 5. Left: Plain CT showing absence of low density area. Right: SPECT showing a low perfusion area around the right thalamus.

現しないからといって安全とは言えないことは周知の事実 である. そのため, 内頸動脈閉塞後の虚血症状出現を予測 する手段として balloon occlusion 時の MSP の測定, dynamic CT, Xe-CT, SPECTによる CBF 測定などが行 われている25)677)911). MSP については一般に $50 \mathrm{mmHg}$ 以上なら安全とされているが, Erbaらは balloon occlusion 直後の CBF 变化と MSP が正確に相関しないため, MSP からは閉塞後の虚血症状を正確に予測できないとし ている2). 今回, balloon Matas testでMSP を測定しえた 6 例のうち虚血症状を生じた 2 例の MSP および，\%MSP は他の 4 例と比較してむしろ高值を示した.このことはそ れらの值だけに頼ると判断を誤る可能性を示唆している.

次に半球血流量についてであるが, Erbaらは balloon occlusion 直後の Xe-CT で, CBF がほとんど変化しない 場合, 両側対称性の血流低下を示す場合, 非対称性の血流 低下を示す場合，および短時間の閉塞にも耐えられない場 
合の 4 グループに分け，最後のグループを除く 3 グループ で中大脳動脈 (MCA) 領域の $\mathrm{CBF}$ がそれぞれ, 順に 40 $\mathrm{m} l / 100 \mathrm{~g} / \mathrm{min}$ 以上, $30 \sim 40 \mathrm{ml} / 100 \mathrm{~g} / \mathrm{min}, 15 \sim 30 \mathrm{ml} / 100$ $\mathrm{g} / \mathrm{min}$ であったとしており, CBF 30 以上の場合をlow risk group としている. そして, low risk groupのうち 3 例で内頸動脈を閉塞し, 虚血症状は出現しなかったと報 告している ${ }^{2)}$. 一方, Linsky らの報告でも $30 \mathrm{ml} / 100$ $\mathrm{g} / \mathrm{min}$ 以上の場合は low risk group としており, 海綿静脈 洞内内頸動脈瘤で low risk group に属する症例のうち 6 例に近位部 ICAの永久閉塞を施行しており，新たな神経 症状の出現はなかったと報告している ${ }^{9)}$ 。また, Erba ら は balloon test occlusion 時の Xe-CT で非対称性の血流低 下を示した 7 例の $\mathrm{CBF}$ が $15 〜 30 \mathrm{ml} / 100 \mathrm{~g} / \mathrm{min}$ と低值で あったことから非対称性の場合には stroke riskが高いと 報告しているが2)，我々の Case 5 やC Case 8 では非対称性 の血流低下を認めるにもかかわらず，患側半球血流量は 41.3 および $40.1 \mathrm{ml} / 100 \mathrm{~g} / \mathrm{min}$ と十分高值を示し, 虚血 症状もなかった。このことから, 血流量の左右差よりもそ の絶対值のほうが重要であると考えられる. 我々の症例の うち，Xe-CTを施行した 6 例は全例 $30 \mathrm{ml} / 100 \mathrm{~g} / \mathrm{min}$ 以 上であり， low risk group に属する。しかし，症例 11 に みられるように，30 以上であっても5 年後に low perfusionを思わせる amaurosis fugax の出現した例がある。ま た，Case 2 の患側血流量も 30 以上であったが，動脈瘤の 血栓化が進行し, しかも前脈絡叢動脈が動脈瘤から分岐し ていたため虚血症状を生じたと考えられる。この場合は皮 質枝よりもむしろ穿通枝領域の虚血であったことから，半 球血流量值からの予測は困難と思われた。

内頸動脈永久閉塞後の虚血症状の原因としては皮質枝の 血流低下，内頸動脈閉塞部遠位端にできた血栓による塞栓 症, および内頸動脈血栓症の上方進行による穿通枝領域の 梗塞がある。我々の症例においては, 虚血症状を生じた 3 例では脳血流量は低下していてもなお $30 \mathrm{ml} / 100 \mathrm{~g} / \mathrm{min}$ 以 上で, critical な血流低下とは言い難く, 虚血症状の出現 を予測できなかった。このうち, amaurosis fugax を生じ た 1 例は長期的にみて一過性の low perfusion を反映して いた可能性があるが，他の 2 例は穿通枝領域の一過性血流 低下，あるいは梗塞によるものであった。したがって，虚 血症状の出現には皮質枝のみならず脳血流量測定では予測 のできない穿通枝の問題 (thrombo-embolism)にも注意を 払う必要があると考えられる。穿通枝系の虚血は症例 2 に みられたように，その派生部に病変がある場合に最も危険 率が高い. したがって, 内頸動脈を永久閉塞する以前に病 変部から穿通枝が派生していないかどうかを十分にチェッ クし，その適応を再考する必要がある。 また，症例 12 の ように穿通枝の起始部に病変がなくてもその近位部の
ICA に狭窄病変がある場合には閉塞末梢側に生じた血栓 が上方進展したり，あるいは近傍の穿通枝に梗塞を生じる 危険があるので，術後数週間は血小板抑制剂や抗凝固剂の 投与を十分に行って厳重に管理する必要があると考えられ る. しかし, 症例 11 のように数年を経過して虚血症状を きたす場合もあるので，その場合には再度脳血流測定を行 って low perfusion が進行しているか否かを検討し, low perfusion の場合はbypass を，そうでない場合は血小板抑 制剂の投与を再開する必要があろう。

\section{結 論}

1. balloon Matas test が陰性で, 患側半球平均血流量が $30 \mathrm{~m} / / 100 \mathrm{~g} / \mathrm{min}$ 以上の場合には血行再建をしないで 内頸動脈を永久閉塞しても皮質枝領域の虚血症状が出 現することは少ないと思われる.

2. stump pressure は穿通枝領域の虚血症状出現を予測す る指標としては必ずしも十分ではない.

3. 虚血症状の出現には皮質枝のみならず穿通枝の問題が 大きく，術前にその安全性と対策を十分に検討する必 要がある.

\section{文献}

1) Brackett CE: The complication of carotid artery ligation in the neck. J Neurosurg 10: 91-106, 1953

2) Erba SM, Horton JA, Latchaw RE, et al: Balloon test occlusion of the internal carotid artery with stable Xenon/CT cerebral blood flow imaging. AJNR 9: 533-538, 1988

3) Fox AJ, Vinuela F, Pelz DM, et al: Use of detachable balloons for proximal artery occlusion in the treatment of unclippable cerebral aneurysms. J Neurosurg 66: 40-46, 1987

4) Gereman WWJ, Black SPW: Cervical ligation for internal carotid aneurysms. An extended follow-up. J Neurosurg 23: 572-577, 1965

5) Handa J, Matsuda M, Nakasu S, et al: Dynamic CT in cerebral vascular diseases. Progress in CT 5: 5-17, 1983

6) Kelly JJ, Collow TF, McBride K, et al: Failure of carotid stump pressures. Arch Surg 114: 1361-1366, 1979

7) LaMuraglia GM, Darling RC, Brewster DC, et al: Neurologic sequelae with internal carotid artery occlusion. Arch Surg 122: 432-435, 1987

8) Leech PJ, Miller JD, Fitch W, et al: Cerebral blood flow, internal carotid artery pressure and EEG as a guide to the safety of carotid ligation. J Neurol Neurosurg Psychiatry 37: 854-862, 1974

9) Linsky ME, Sekhar LN, Horton JA, et al: Aneurysms of the intracavernous carotid artery: A multidisciplinary approach to treatment. J Neurosurg 75: 525-534, 1991

10) Morioka T, Matsushima $\mathrm{T}, \mathrm{Fujii} \mathrm{K}$, et al: Balloon test occlusion of the internal carotid artery with monitoring of compressed spectral arrays (CSAs) of electroencephalogram. Acta Neurochir (Wien) 101: 29-34, 1989

11) Terada $T$, Nishiguti $T$, Hyotani $G$, et al: Assessment of risk of carotid occlusion with balloon Matas testing and dynamic CT. Acta Neurochir (Wien) 103: 122-127, 1990

Surgery for Cerebral Stroke $21: 1993$ 